\title{
Educação comparada internacional: percepções sobre a formação de professores no Brasil e na Alemanha
}

\section{International comparative education: perceptions of teacher training in Brazil and Germany}

\author{
Catia Piccolo Viero Devechi* \\ Gionara Tauchen ${ }^{* *}$ \\ Helza Ricarte Lanz ${ }^{* * *}$
}

\section{Resumo}

O estudo hermenêutico, ainda em desenvolvimento, realizado no âmbito da educação comparada internacional, abordará, para fins de análise de uma interface do estudo, a política em educação no que se refere à formação docente para os anos iniciais do ensino fundamental no Brasil e na Alemanha, bem como a sua relação com a educação internacional. Objetivamos compreender e problematizar as concepções que têm permeado essa formação nos dois países, tendo em vista que ocorreram modificações substantivas na última década. Ambos os países precisaram se adaptar às exigências legais, como a resolução CNE/CP n. 1/2006, no caso do Brasil, e a Declaração de Bolonha em 1999, no caso da Alemanha. No Brasil, os cursos de pedagogia precisaram atender ao enfoque da formação de professores para a Educação Infantil e primeiros anos do Ensino Fundamental, da formação de pesquisadores e gestores. Na Alemanha, os cursos precisaram se adaptar aos graus acadêmicos de forma equivalente aos demais países europeus, adotando um sistema baseado em duas fases: bacharelado ( 3 anos) e mestrado ( 2 anos); e vários estágios práticos. Percebe-se que, mesmo com perspectivas, estruturas, contextos e problemas diferentes, há uma tendência de formação docente decorrente da globalização internacional cada vez mais tecnificada e menos emancipadora.

Palavras-chave: Educação comparada. Formação de professores. Política educacional.

\section{Abstract}

This ongoing hermeneutic study, performed in the field of international comparative education, will, for the purpose of analyzing an interface of the study, address educational policy regarding teacher education for the initial years of elementary education in Brazil and in the Germany, as well as its relationship with education internationally. We aim to understand and problematize the conceptions that have permeated this education in both countries, considering that substantive changes have occurred in the last decade. Both countries have had to adapt to legal requirements, such as resolution CNE / CP n. 1/2006, in the case of Brazil, and the Bologna Declaration in 1999, for Germany. In Brazil, pedagogy courses have had to focus on the training of teachers for Early Childhood Education and early years of Elementary Education, and the training of researchers and managers. In Germany, courses have had to adapt to academic degrees in a way equivalent to other European countries, adopting a system based on two phases: baccalaureate ( 3 years) and masters ( 2 years); and various practical stages. It can be seen that, even with different perspectives, structures, contexts and problems, there is a trend towards teacher training that is increasingly technicized and less emancipatory, as a result of international globalization.

Keywords: Comparative Education. Teacher training. Educational politics.

\section{Recebido em: 28/07/2016 - Aprovado em: 15/10/2016 http://dx.doi.org/10.5335/rep.v24i1.6994}

Professora do Programa de Pós-Graduação em Educação da Faculdade de Educação da Universidade de Brasília. Doutora em Educação pela Universidade Federal de Santa Catarina - UFSC. E-mail: devechi@unb.br

** Professora Adjunta da Universidade Federal do Rio Grande - FURG, atuando nos Programas de Pós-Graduação em Educação e em Educação em Ciências: Química da Vida e Saúde. Possui doutorado em Educação (PUC/RS) e pós-doutorado na Universidade Eduardo Mondlane (UEM/MZ). E-mail: giotauchen@gmail.com

*** Docente e Pesquisadora no Instituto de Filosofia da Educação, Antropologia e Pedagogia Continuada (Institut für Bildungsphilosophie, Anthropologie und Pädagogik der Lebensspanne), Colônia Alemanha. Doutora em Ciências Sociais pela Universidade de Friburgo, Suíça. E-mail: hl@drlanz.org 
Historicamente, a educação comparada envolveu-se com uma diversidade de preocupações, princípios, abordagens e formas de intervenção, mas o Estado-nação sempre esteve no seu âmago (GOERGEN, 1991; MONARCHA; LOURENÇO FILHO, 2004; MALET, 2004; DALE; ROBERTSON, 2012), tornando-se princípio organizador e personificando o projeto da modernidade, principalmente com os Estados pós-coloniais criados a partir da Segunda Guerra Mundial. Nesse sentido, a comparação das semelhanças e das dessemelhanças, entre os sistemas educativos nacionais, como estratégia para orientar as reformas educativas, até os estudos visando à produção de sentidos e de solidariedades simbólicas (COWEN; KAZAMIAS; ULTERHALTER, 2012; KOTTHOFF; KLERIDES, 2015), os quais estão inscritos na história da educação comparada, revelam a importância de estudos internacionais. Dale (2004, p. 441) se refere a uma "agenda globalmente estruturada para a Educação", elaborada e definida por "[...] forças supranacionais, assim como por forças político-econômicas nacionais". Então, como os entendimentos sobre as políticas em educação e formação docente se expressam em tempos de globalização e de internacionalização da educação?

Kazamias (2012) diz que, historicamente, a educação comparada ocupou-se, principalmente, do estudo dos sistemas educacionais, das instituições, das políticas e das reformas educacionais. Os estudos nessas áreas foram desenvolvidos nos contextos nacionais, transnacionais e transculturais, mas secundarizaram as relações com o "conhecimento educacional ou ao conteúdo dos currículos, e à pedagogia; em outras palavras, aos aspectos intrínsecos da educação" (KASAMIAS, 2012, p. 193). No presente estudo, procuramos discutir a proposta de formação de professores para os anos iniciais no Brasil e na Alemanha a partir de uma abordagem comparada internacional fundamentada na hermenêutica reconstrutiva (DEVECHI; TREVISAN, 2010), encaminhando-nos no sentido de uma aprendizagem internacional guiada pela compreensão.

O estudo, ainda em desenvolvimento, realizado no âmbito da educação comparada internacional, abordará para fins de análise de uma interface do estudo, a política em educação, no que se refere à formação docente para os anos iniciais do ensino fundamental. Objetivamos compreender e problematizar as concepções que têm permeado essa formação nos dois países, tendo em vista que ocorreram modificações substantivas na última década. Ambos os países precisaram se adaptar às exigências legais, como a Resolução CNE/CP n. 1/2006, no caso do Brasil, e a Declaração de Bolonha em 1999, no caso da Alemanha (OELKERS, 2012; TERHART, 2014). No Brasil, os cursos de pedagogia precisaram atender ao enfoque da formação de professores para a Educação Infantil e primeiros anos do Ensino Fundamental, da formação de pesquisadores e gestores (BRASIL, 2006). Os cursos passaram a ter múltiplas atribuições, exigindo uma reorganização curricular por 
meio de uma dispersão de disciplinas que, até hoje, é razão para tensões e impasses nas faculdades de educação. Na Alemanha, os cursos precisaram se adaptar aos graus acadêmicos de forma equivalente aos demais países europeus, adotando um sistema baseado em duas fases: bacharelado (3 anos) e mestrado (2 anos); e vários estágios práticos (KMK, 2010; OELKERS, 2012; WALM; WITTEK, 2014).

Neste sentido, nos colocamos no desafio de conhecer essas políticas que, mesmo com contextos socioeconômicos e histórias diferentes, podem contribuir com a ampliação das nossas compreensões sobre algumas dimensões dos desafios da formação de professores no âmbito internacional. Nesse momento, colocamos nossas percepções em interação com algumas experiências da Alemanha, que também passam por mudanças fundamentais devido à necessidade de adaptação ao processo de Bolonha (1999) e vêm desenvolvendo políticas de garantia da qualidade da formação para o magistério, bem como, políticas de maior internacionalização e mobilidade entre os Estados.

Assim sendo, discutiremos a formação do docente dos anos iniciais a partir da comparação das Diretrizes legais para a formação de professores nos dois países, analisando o foco almejado para a formação, a estrutura dos cursos e seus enfoques. Conhecendo esses elementos da formação, nos dois países, procuramos discutir a profissionalização do pedagogo e dos professores, bem como a importância da internacionalização dos estudos no que se refere à formação do docente. Para tanto, faremos uma breve apresentação das Diretrizes para a formação de docentes de cada um dos países, sendo que, no contexto da Alemanha, serão apresentadas as Diretrizes do Estado de Renânia Norte-Vestefália, tendo em vista que apesar dos acordos entre os Estado, em relação a diversas questões sobre a formação docente, cada Estado tem uma legislação própria.

\section{Diretrizes Curriculares Nacionais para o curso de Pedagogia e para a formação de professores no Brasil}

Os cursos de pedagogia, no Brasil, tiveram que se adaptar às Diretrizes de 2006, e ainda precisam se adaptar às Diretrizes de 2015 para a formação de professores. $\mathrm{O}$ foco dos cursos deve ser o atendimento ao Plano Nacional de Educação (2014-2024) em relação à necessidade de aproximação das licenciaturas com escola básica, tendo em vista as diversas dificuldades e problemas identificados nesse nível de ensino, inclusive pelos processos de avaliação internacional.

As Diretrizes Curriculares Nacionais para o Curso de Pedagogia foram consolidadas nos Pareceres CNE/CP nº 05/2005, nº 01/2006 e na Resolução CNE/CP nº 
01/2006. Tais diretrizes definiram os princípios, as áreas de atuação e abrangência da formação em pedagogia. Se aplicam ao curso:

[...] formação inicial para o exercício da docência na educação infantil e nos anos iniciais do ensino fundamental, nos cursos de ensino médio, na modalidade normal, e em cursos de educação profissional na área de serviços e apoio escolar, bem como em outras áreas nas quais seja previstos conhecimentos pedagógicos (BRASIL, 2006, p. 1).

A formação do pedagogo deve ter como base o exercício docente nas diferentes modalidades, articulando, com as atividades de gestão e de pesquisa educacional. A ideia é formar o pedagogo a partir de três pilares indissociáveis: professor, gestor e pesquisador. A base da formação é a docência, entendida num sentido ampliado, em que se articula com as atividades pedagógicas a serem desenvolvidas em espaços escolares e não escolares. Ou seja, trata-se da formação de docentes que tenham condições de trabalhar em diferentes espaços pedagógicos, de participar da gestão e de produzir conhecimento na área.

Diante dessa objetivação de docência, o curso de pedagogia deve propiciar aos estudantes os seguintes estudos teórico-práticos: planejamento, execução e avaliação de atividades educativas; conhecimentos filosóficos, histórico, antropológico, ambiental-ecológico, psicológico, linguístico, sociológico, político, econômico e cultural. Deverá também oferecer conhecimentos teóricos e práticos plurais que possam ser consolidados no exercício da profissão, fundamentando-se em princípios de interdisciplinaridade, contextualização, democratização, relevância social, ética e estética.

O egresso do curso deverá demonstrar consciência da diversidade, compromisso com uma sociedade justa, equânime e igualitária, almejando superar as exclusões sociais, étnico raciais, econômicas, culturais, religiosas, políticas, necessidades especiais, escolhas sexuais. Além disso, deverá estar em condições de educar crianças de 0 a 5 anos e de fortalecer as aprendizagens de crianças/adultos do ensino fundamental, trabalhar em espaços escolares e não escolares, ensinar língua portuguesa, matemática, ciências, história, geografia, arte, educação física. $\mathrm{E}$, ainda, demonstrar domínio das tecnologias de informação e comunicação, participar na organização e gestão de sistemas de ensino, ter postura investigativa, ter condições de realizar o diálogo entre conhecimentos valores, modos de vida, orientações filosóficas, políticas e religiosas próprias à cultura do povo indígena, ou de escolas remanescente de quilombos ou que se caracterizem por receber populações de etnias e culturas específicas (BRASIL, 2006).

Em relação à organização dos cursos, foram previstos três núcleos: estudos básicos, aprofundamento e diversificação e estudos integradores. À cada núcleo foram apresentadas as diferentes tarefas e ações a serem realizadas em contextos 
escolares e não escolares, não propriamente componentes curriculares. O núcleo de estudos básicos deverá ser constituído pela aplicação de princípios, concepções de critérios oriundos das diferentes áreas do conhecimento relevantes para a pedagogia; pela aplicação de princípio de gestão democrática; análise, planejamento e implementação de processos e experiências educacionais; utilização de conhecimentos multidimensionais sobre o ser humano em situações de aprendizagem; aplicação de conhecimentos de processos de desenvolvimento de crianças, adolescentes, adultos; realização de diagnóstico de diferentes forças e interesses da sociedade e considerá-los no plano pedagógico; planejamento, execução e avaliação de experiências que considerem o contexto histórico e sociocultural do sistema educacional brasileiro; estudo da didática, das teorias e metodologias pedagógicas, de processos de organização do trabalho docente; decodificação e utilização de códigos de diferentes linguagens utilização por crianças, além do trabalho didático com conteúdos relativos à língua portuguesa, matemática, ciências, história, geografia, artes e educação física; estudos das relações entre educação e trabalho, diversidade cultural, cidadania e outras problemáticas das sociedade atual; atenção às questões referentes à ética, à estética e à ludicidade no contexto do exercício profissional; estudos, aplicação dos textos legais relativos à organização da educação nacional (BRASIL, 2006).

O núcleo de aprofundamento e diversificação de estudos deverá estar voltado às áreas de atuação profissional priorizadas pelo projeto pedagógico das instituições, oportunizando investigações sobre processos educativos e de gestão; avaliação, criação e uso de textos, materiais didáticos, procedimentos que contemplem a diversidade social e cultural da sociedade brasileira; estudos, análise e avaliação de teorias da educação (BRASIL, 2006). O aprofundamento em uma ou mais modalidades de ensino específico deverá "ser comprovado, para os devidos fins, pelo histórico escolar do egresso, não se configurando de forma alguma uma habilitação" (BRASIL, 2005, p. 10).

O núcleo de estudos integradores deverá compreender a participação em seminários e estudos curriculares, projetos de iniciação científica, monitoria e extensão; atividades práticas nas diferentes áreas do campo educacional; atividade de comunicação e expressão cultural.

Em relação à organização e integralização dos estudos, o curso deverá oferecer disciplinas, seminários e atividades teóricas educacionais; práticas de docência e gestão educacional, atividades complementares (monitoria, trabalho de final de curso, iniciação científica, etc.), estágio curricular na Educação Infantil e nos anos iniciais do Ensino Fundamental; nas disciplinas pedagógicas dos cursos de ensino médio, na modalidade normal; na educação profissional na área de serviços e de apoio escolar; na Educação de Jovens e Adultos; na participação em atividade de gestão de processos educativos (BRASIL, 2006). Deverão ser observados: 
[...] os princípios constitucionais e legais, a diversidade social, étnico-racial e regional do país, a organização federativa do estado brasileiro, a pluralidade de ideias e concepções pedagógicas, o conjunto de competências dos estabelecimentos de ensino e dos docentes previstas nos arts. 12 e 13 da LDB/1996 e o princípio da gestão democrática (BRASIL, 2005, p. 10).

Em relação à carga horária, o curso deverá alcançar o mínimo de 3.200 horas, sendo 2.800 horas para aulas, seminários, pesquisa, participação em grupo de estudo; 300 horas dedicadas ao estágio supervisionado, que deverá ser realizado ao longo do curso, com prioridade para a Educação Infantil e anos iniciais do Ensino Fundamental e em áreas que correspondam ao projeto pedagógico de cada instituição; bem como 100 horas de atividades de aprofundamento em áreas de interesses dos alunos por meio da extensão, iniciação científica e monitoria.

No entanto, apesar da aprovação das Diretrizes específicas da pedagogia ser considerada uma conquista, diversas dúvidas e descontentamentos ainda persistem, apesar das reivindicações históricas das principais entidades acadêmicas da área terem sido atendidas. Podemos dizer que as DCNP contribuíram com a formação dos professores dos anos iniciais que passaram a ter a garantia de um curso de graduação plena nas universidades, mas, ao mesmo tempo, ativaram várias outras preocupações, tais como: a dificuldade de formar um único profissional para trabalhar em diferentes modalidades de ensino; a dificuldade de formar os pedagogos para atuar em espaços educacionais não escolares e escolares; o corpo docente dos cursos de pedagogia das instituições públicas que nem sempre possui formação para docência (a maior parte dos professores foi concursada para trabalhar no modelo de curso com as habilitações); a falta de espaço para tratar das questões epistemológicas da pedagogia; a desvalorização das disciplinas de fundamentos da educação, etc. Ou seja, o curso parece não estar conseguindo organizar a formação nem do professor para a Educação Infantil, nem o professor dos anos iniciais, nem do gestor, nem do pesquisador e nem o profissional que irá trabalhar em espaços não escolares, nem os especialistas da educação. Isso significa que há um descompasso entre o que as diretrizes estabelecem e as reais possibilidades de um curso de graduação de 4 anos. Ou seja, mudou-se a Lei sem a avaliação da viabilidade da proposta. Além disso, não há como negar que o texto da Resolução é confuso, ambíguo, faltando clareza em relação aos seus conceitos e ao percurso curricular proposto.

Diante das discussões e dos movimentos realizados em torno do descontentamento das Diretrizes nacionais para formação de professores da escola básica de 2002 e das Diretrizes nacionais para os cursos de pedagogia de 2006, a necessidade de articular a Educação Superior com a escola básica, somados às metas do Plano Nacional de Educação - PNE para o decênio de 2014/2024, que busca melhoria na 
formação inicial e continuada de profissionais do magistério da Educação Básica ${ }^{1}$, foi aprovado, mais recentemente, em 2015, a Resolução de n. 2 que institui as Diretrizes Curriculares Nacionais para a formação inicial em nível superior (cursos de licenciatura, cursos de formação pedagógica para graduados e cursos de segunda licenciatura) e para a formação continuada. Tais Diretrizes apresentam mudanças significativas em relação às questões apontadas como problemáticas: tempo de estágio, desarticulação dos cursos com a Educação Básica, pouca ênfase na gestão do sistemas educacionais, reduzida articulação das Diretrizes Curriculares Nacionais para a Formação Inicial e Continuada em Nível Superior e as Diretrizes Curriculares Nacionais para a Educação Básica; falta de uma base comum nacional capaz de nortear a formação inicial e continuada no país.

Em relação ao tempo de atividade prática, houve um aumento significativo das horas dedicadas ao estágio supervisionado, passando de 300 para 400 horas, somadas a 400 horas de prática como componente curricular, distribuídas ao longo do processo formativo na área de formação e de atuação na Educação Básica. O conhecimento acerca da complexidade da escola é mais enfatizado, o que se confirma pela carga horária voltada para a prática. O propósito parece ser aproximar o estudante dos desafios escolares e com o conhecimento sobre escola. A gestão ganha relevo, pois se associa o docente à função de gestor, prevendo sua formação para atuar na organização e na administração da escola básica.

Buscando atender às metas do PNE em relação à melhoria e à organização da escola básica, a Resolução estabelece uma base comum nacional de concepção de formação pautada

[...] pelo desenvolvimento de sólida formação teórica e interdisciplinar em educação de crianças, adolescentes, jovens e adultos (as) e nas áreas específicas de conhecimento científico quanto pela unidade entre teoria e prática e pela centralidade do trabalho como princípio educativo na formação profissional, como também pelo entendimento de que a pesquisa se constitui em princípio cognitivo e formativo e, portanto, eixo nucleador dessa formação (DOURADO, 2015, p. 301).

Para atender à necessidade de articulação entre a Educação Superior e a Educação Básica, as DCNs estabelecem que as instituições formadoras devem institucionalizar o projeto de formação com identidade própria, em consonância com o Plano de Desenvolvimento Institucional (PDI), o Projeto Pedagógico Institucional (PPI) e o Projeto Pedagógico de Curso (PPC) (BRASIL, 2015). Trata-se de uma forte preocupação com o atendimento, por parte dos cursos, da demanda da escola básica.

Apesar de não serem Diretrizes específicas para a pedagogia, tais encaminhamentos terão que ser considerados pelos cursos, que terão dois anos para revisarem 
seus projeto pedagógicos. Podemos dizer que as Diretrizes avançaram em relação as Diretrizes de 2006 para os curso de pedagogia, principalmente, em relação ao tempo de estágio, foco no conhecimento da complexidade da escolar, na formação para a gestão e formação teórica. Tais apontamentos já haviam sido feitos nas Diretrizes de 2006, mas reaparecem nas Diretrizes de 2015 com mais proeminência. Ou seja, a ênfase na docência é reforçada, distanciando-se da ideia de formação do especialista em educação.

O curso de pedagogia parece ter ficado mais próximo das demais licenciaturas com foco na docência, com diferença de estar focado em mais de um objeto de ensino: docência na Educação Infantil e docência anos iniciais do Ensino Fundamental, sendo maior a carga horária para o conhecimento dos objetos de ensino. Segundo as Diretrizes,

[...] nas licenciaturas em educação infantil e anos iniciais do ensino fundamental, cursos de pedagogia, a serem desenvolvidos em projetos de cursos articulados, deverão preponderar os tempos dedicados à constituição de conhecimento sobre os objetos de ensino e, nas demais licenciaturas, o tempo dedicado às dimensões pedagógicas não será inferior à quinta parte da carga horária total (BRASIL, 2015, p. 14).

Isso significa que além da formação, prioritariamente, em duas modalidades de licenciatura, o curso ainda contemplaria, implicitamente, o bacharelado para o aprofundamento nos saberes pedagógicos. Assim, enquanto nas demais licenciaturas se estuda no mínimo 4/5 de conteúdo específico e 1/5 de disciplinas pedagógicas; na pedagogia, se estudaria, preponderadamente, as disciplinas pedagógicas, com um espaço menor para a formação nas duas principais especificidades exigidas, além de outras, conforme as condições de cada instituição.

\section{Os cursos de formação de professores para os anos iniciais na Alemanha: a experiência do Estado da Renânia do Norte-Vestfália}

Com o processo de Bolonha (1999), os países da União Europeia assumiram o compromisso de realizar reformas em suas estruturas educacionais e sistemas de ensino (OELKERS, 2012). O objetivo foi criar uma maior convergência entres os sistemas de ensino e, desse modo, possibilitar a mobilidade internacional dos estudantes, os estudos de educação comparada e fomentar a internacionalização das universidades. Na Alemanha ${ }^{2}$, a maioria das instituições acadêmicas já realizou a reforma do ensino superior que passou a se organizar em dois níveis: o bacharelado (6 - 7 semestres, dependendo da instituição, o B.A. é a base de qualificação para o mestrado) e o mestrado profissionalizante ( 2 anos, voltado para o mercado de 
trabalho). Além do sistema sequencial entre bacharelado e mestrado, a maioria das instituições se adequou também ao sistema europeu de transferência de créditos (European Credit Transfer Systems - ECTS) e ao processo de comparação cooperativa de qualidade do ensino, que tem como objetivo promover a empregabilidade e a competitividade do sistema europeu de ensino superior. Tratou-se de uma abertura das universidades no sentido de atender às demandas requeridas e acertadas no âmbito europeu.

Tal reforma atingiu todos os cursos, incluindo os cursos de formação para o magistério ${ }^{3}$. Devido à peculiaridade do sistema educacional alemão, existem vários cursos de formação de docentes no país ${ }^{4}$ (WALM; WITTEK, 2014). Tais cursos estão direcionados aos diferentes tipos de escolas: Grundschulen, Hauptschulen, Realschulen, Gymnasien e Gesamtschulen, ${ }^{5}$ escolas especiais (Sonderschulen) e escolas profissionalizantes (Berufsschulen). Segundo Puderbach (2016), essa divisão clássica (tripé) das escolas se encontram apenas quatro dos dezesseis estados alemães, isto é, na Baviera (Bayern), em Hessen, na Renânia do Norte-Vestfália e na Baixa Saxônia (Niedersachsen). Nos outros Estados, existe uma grande variedade de formas mistas como, por exemplo, da Gesamtschule, às vezes, unificando a Hauptschule com a Realschule em uma escola do nível médio: a Mittelschule (PUDERBACH, 2016, p. 48).

O sistema de ensino na Alemanha é gratuito e de responsabilidade do Estado, exceto a educação infantil pré-escolar que é, em parte, mantida pelo Estado e, em parte, por igrejas e iniciativa privada. Cada Estado da federação alemã tem autonomia sobre o seu sistema educacional que, dentro dos dezesseis Estados alemães, como já mencionado, pode variar muito (OELKERS, 2012). As Conferências dos Ministros da Cultura (KMK) e as Conferências dos Reitores das Universidades (HRK) elaboram sugestões para as diretrizes educacionais, as quais permitem variações na formação superior para o exercício do magistério (KUHN, 2014).

Assim, devido à especificidade do sistema alemão, para maior compreensão sobre o sistema superior de formação de professores na Alemanha em comparação com o Brasil, analisaremos, nesse artigo, o Estado da Renânia do North-Vestfália. Nesse Estado, todos cursos são universitários e seguem a lei de diretrizes (Lehrerausbildungsgesetz $-L A B G$ ), que entrou em vigor no dia 26 de maio de 2009 , tendo a sua última revisão em junho de 2016. Segundo essa lei, o Estado e as universidades devem se comprometer com a formação dos docentes para o magistério, levando em consideração os desafios educacionais e as necessidades das escolas nas suas diferentes especificidades. Assim, para se tornar docente do nível primário ao secundário, nesse Estado, é necessário realizar um curso de bacharelado (6 semestres ou 180 créditos) e um curso de mestrado (4 semestres ou 120 créditos) focados no 
tipo de escola que se pretende lecionar. Além dessa formação, que inclui 3 estágios ao longo do bacharelado e mestrado, inclusive o semestre prático (praxissemester) no mestrado enquanto elemento inovador desse processo de reforma (RICARTE LANZ, 2016). Além disso, é necessário realizar um último estágio profissional de dezoito meses no tipo de escola escolhida.

Começando na Renânia do Norte-Vestfália, foi iniciada a unificação da duração da formação (para o magistério em 10 semestres para todos os curso com o estágio preparatório (Refendariat) de um ano e meio (TERHART, 2014, p. 8, tradução nossa).

Os docentes, de todos os tipos de escola, podem lecionar uma combinação de duas disciplinas ou áreas do conhecimento. Ou seja, um docente é formado para lecionar em um determinado tipo de escola e em duas áreas do conhecimento ou disciplinas específicas. Tais disciplinas são escolhidas pelo estudante antes e durante o processo de formação a partir das combinações oferecidas pelas universidades. A faculdade/instituto de educação, geralmente, é constituída por um núcleo de pedagogia geral, sendo concomitantemente de responsabilidade de outras faculdades, a capacitação para a docência nas diferentes disciplinas do currículo escolar: Música, Arte, Física, Matemática, Letras, Geografia, Química, Educação Física, Religião, etc. Cabe à faculdade/ instituto de educação oferecer aos estudantes uma formação básica sobre questões educacionais, da escola, dos processos de ensino, da primeira experiência na escola, da aprendizagem, dos processos sociais e diagnósticos, da didática e dos conceitos pedagógicos específicos dos diferentes tipos de escola, além de orientar os trabalhos de final de curso.

A LABG (2009) explicita que o objetivo dos cursos de formação para o magistério deve ser a preparação do docente para exercer a profissão de forma autônoma. Para tanto, a formação é dividida em duas partes: uma parte de estudo e outra de preparação prática. Os cursos devem capacitar os estudantes para uma abordagem profissional voltada à diversidade, em particular a um sistema de educação inclusiva e cooperativa. É tarefa da formação promover as qualificações necessárias para o reconhecimento das potencialidades e habilidades individuais de todos os alunos.

O curso de bacharelado inclui componentes específicos de ensino e devem ser estruturados para que os estudantes possam adquirir competências que os permitam carreiras fora da escola. No entanto, apenas com o bacharelado, os estudantes têm poucas chances de conseguir um trabalho, mesmo fora de escolas e são orientados para fazer o mestrado. O curso de mestrado (Master of Education) prepara os alunos especificamente para o magistério. $O$ estudo nas duas fases inclui ciências de formação (ciências da educação, sociologia e psicologia), disciplinas específicas, formação didática, avaliação e aconselhamento, incluindo a fase dos estágios práticos. Baseia-se no desenvolvimento das competências profissionais básicas, ad- 
quiridas numa estrutura módulos de estudo. As universidades não se utilizam do sistema de disciplinas, como no Brasil, mas seguem o modelo de módulos, em que o próprio estudante escolhe a sua trajetória com uma carga horária determinada. A formação, em cada modulo, é livre, constituída por aulas expositivas (Vorlesungen), seminários, cursos com estudos presenciais, on-line e estágios práticos. O diploma do bacharelado chama-se "Bacharelado em Artes, B.A." e o de mestrado "Mestrado em Educação, M.A. Education". Nos Exames de Estado (Staatsexamen) ficam registrados o tipo de escola e as disciplinas que o estudante se especializou, habilitando o aluno para o ingresso no magistério. Só após o Staatsexamen, o docente está apto a se candidatar para um posto de trabalho como professor numa escola.

Os estágios, durante o bacharelado e o mestrado, são de responsabilidade da universidade, do centro de formação docente (ZfL) e da escolas e seguem os critérios regulamentados pelos decretos de acesso ao magistério (Lehramtzugangsverordnung - LZV, 2009) do Estado. O Ministério da Educação do Estado, em comum acordo com as universidades e as escolas, determina previamente os objetivos do estágio e as necessidades do magistério. No bacharelado, os estudantes devem cumprir com duas fases práticas: 1) um estágio de orientação e aptidão de pelo menos 25 dias durante um semestre, geralmente no primeiro ano. Trata-se de um estágio voltado para discussão crítica-analítica da prática escolar, para reflexão da aptidão para a profissão docente e para o desenvolvimento de uma perspectiva orientada para profissão em estudos posteriores. A parte do estágio de orientação objetiva a reflexão sobre a complexidade do campo da ação na escolar, a partir de uma perspectiva profissional, estabelecendo as primeiras relações entre abordagens teóricas das ciências da formação e situações pedagógicas concretas. A parte do estágio de aptidão tem como objetivo permitir ao estudante a reflexão sobre a situação dos estudantes enquanto aprendizes individuais sobre o papel do docente, sobre os campos de aprendizagens e práticas relativos à escola, as próprias possibilidades de ação no campo pedagógico, bem como a reflexão da escolha da profissão. 2) Um estágio profissional em outros espaços pedagógicos de pelo menos quatro semanas. Tal estágio oferece aos estudantes oportunidades de carreira fora da profissão docente.

No mestrado, os estudantes devem realizar um estágio (3) de cinco meses na escola (750 horas), ministrando aulas pelo menos a metade do tempo de trabalho. Como Ricarte Lanz (2016) afirma, na Universidade de Colônia, por exemplo, as atividades de prática de aula e de pesquisa empírica são a base do semestre prático no mestrado, cuja duração é de um ano letivo, isto é, 750 horas/aulas de teoria e prática em sala de aula, sendo 360 horas na universidade e 390 horas nas escolas e nos centros de formação docente (ZfL). O propósito é que o estudante 
tenha oportunidade de planejar, realizar e refletir sobre elementos fundamentais do ensino e da aprendizagem escolar com base na disciplina escolhida, na didática dessa disciplina e nas ciências da formação. Trata-se de um momento de aplicação e reflexão dos conceitos e procedimentos para a avaliação dos rendimentos, diagnóstico pedagógico e incentivos individuais. A ideia é de que o estudante possa questionar a teoria a partir da prática, e questionar a prática a partir da teoria, além de desenvolver um perfil profissional próprio. Refletir sobre suas ações, saber pesquisar, ministrar aulas, dialogar, documentar, comunicar e compartilhar seus conhecimentos são competências-chave que contribuem para um elevado grau de profissionalismo pedagógico para o exercício do magistério (COMBE; KOLBE, 2008; FAULSTICH-WIELAND; FAULSTICH, 2008; HÖRSTER 2010; RICARTE LANZ, 2016; ROTERS, 2012).

De regra, os estágios (1 e 3) devem ser feitos no tipo de escola e disciplina que o estudante quer se especializar. $\mathrm{O}$ semestre prático serve para ter uma ideia do campo de trabalho para os estudos posteriores e para o estágio profissional. O estágio é realizado em cooperação com as escolas e com os centros de formação de professores ${ }^{6}$ presentes nas universidades. Trata-se de momentos práticos que permitem aos estudantes uma reflexão sobre a aptidão para a docência. A prática é realizada em escolas públicas que contribuem para a formação do estudante universitário que quer se tornar professor. É de responsabilidade da escola contribuir para a formação prático-escolar do estudante, que deve encarregar alguns docentes plenos para o trabalho co-adjunto de orientação/supervisão com os centros (ZfL) e as universidades. $\mathrm{O}$ ministério da educação poderá estabelecer alguns critérios de organização e distribuição desses estágios, bem como diretrizes sobre os direitos e deveres dos estagiários (LZV, 2009).

Além dos estágios no bacharelado e no mestrado, depois de formado, é necessário realizar um estágio profissional de 18 meses na escola. Tal estágio é administrado pelo estado. O Estado coordena e avalia as condições de admissão (pessoal, espacial, estrutural, orçamento) e oferece uma bolsa de estágio (KMK, 2011). O tipo de estágio e as disciplinas do estágio devem ser compatíveis com as "especializações" realizadas nos cursos de bacharelado e mestrado. Existe, entre os Estados, um acordo que foi alcançado na Conferência dos Ministérios, que se chamou de "Standard para a formação de docente: ciências da educação" que determina as competências a serem alcançadas, os critérios relativos aos conteúdos dos saberes da disciplina e da didática da disciplina, além do número mínimo de 300 créditos (180 de bacharelado e 120 de mestrado), como requisito para que os docentes possam realizar o estágio profissional em qualquer Estado. Como competências gerais, o docente deve saber utilizar pedagogicamente os recursos tecnológicos de 
informação e comunicação; saber incentivar os estudantes com histórico de imigração uma formação intercultural; ter competência para participar e contribuir para o desenvolvimento escolar; ter conhecimento de duas línguas estrangeiras. A ideia foi padronizar alguns elementos para permitir o reconhecimento dos diplomas entre todos os estados (LZV, 2009; KMK, 2010; KMK, 2011).

Para adquirir uma qualificação para a docência, além de realizar um estágio profissional, é necessário realizar o exame do Estado para saber se os candidatos atingiram o objetivo da formação (LZV, 2009). O Ministério da Educação do Estado, em conjunto com o Ministério do Interior e do Ministério das Finanças, elabora e regulamenta o exame do Estado para o ensino nas escolas e autoriza a realização do exame (KMK, 2011). No que se refere ao curso de formação de professores para o ensino primário (Grundschule) é exigido uma formação básica em linguagem escrita (alfabetização) e em matemática para esse nível de ensino e outra área de ensino de livre escolha, incluindo a didática, os estudos de ciências da educação focados na aprendizagem precoce (frühes Lernen), articulados com pedagogia especial e a formação para os anos primários. No caso da outra área de ensino ser uma língua estrangeira, o estudante deverá ficar num país em que a língua vernácula seja a língua que está sendo estudada por, no mínimo, três meses. Existe, ainda, a possibilidade de adquirir um perfil profissional por meio do estudo aprofundado do ensino da língua alemã como segunda língua. No caso de a opção ser as disciplinas de artes, música e esporte, o estudante deverá demonstrar aptidão, sendo a conclusão da área avaliada em exames práticos (LZV, 2009).

A grade curricular dos cursos de formação de professores para o magistério, incluindo bacharelado e mestrado para o magistério nos anos elementares, é composta por 300 créditos e está estruturada pelas seguintes áreas de estudo: Áreas de Estudo I: Língua escrita (alfabetização); Área de Estudo II: Matemática e conceitos básicos matemáticos; Área de Estudo III: Ciências (naturais, sociais ou estética), didática específica de uma disciplina; Aprofundamento das áreas I, II ou III ou de uma disciplina específica; Ciências da formação, pedagogia para a escolar primária inclusive: elementos práticos, conceitos de processos de aprendizagem precoce, conceitos de pedagogia especial, diagnósticos e apoio didático; alemão como segunda língua para crianças de migrantes; semestre prático durante o mestrado; Trabalhos de conclusão de curso de bacharelado e mestrado. Na área de estudo III são realizados os estudos das ciências naturais, ciências sociais e educação estética. Também é possível a formação para o ensino nas seguintes disciplinas: inglês, arte, música, religião evangélica, religião católica e esporte. O estudante também tem a opção de se dedicar ao ensino do alemão para migrantes, estudando a língua de origem dos imigrantes em até a metade dos créditos. 
A formação de professor no Estado de Renânia do Norte-Vestfália apresenta uma forte preocupação com a articulação entre teoria e prática pedagógica nos cursos de formação para o magistério, tendo em vista a realização obrigatória de um estágio de orientação de aptidão para o magistério (25 dias) e de um estágio em outros campos profissionais (4 semanas) no bacharelado, da realização de 750 horas de prática escolar no mestrado e dos 18 meses de estágio profissional remunerado. Há uma fundamentação teórica ampla nas ciência da formação (ciência da educação, sociologia e psicologia), nas disciplinas específicas e nas respectivas didáticas, sendo perceptível o esforço para uma individualização da aprendizagem (CRAMER, 2014). Além disso, há também uma grande preocupação como o conhecimento e uma postura reflexiva sobre a escola, a qualidade da profissionalização e aptidão dos docentes. A carga horária também é bastante extensa comparando com a carga horária dos cursos de formação de professores no Brasil. São 9.000 horas $^{7}$ previstas entre mestrado e bacharelado (estudos presenciais, online e individuais) e 18 meses de estágio profissional na escola. A carga horária entre as áreas de aprendizagem e de prática é distribuída de forma aproximada com 55 créditos para cada disciplina de especialização, com 12 créditos de aprofundamento em uma disciplina, 64 créditos para o estudo das ciências da educação, incluindo os estágios feitos durante o bacharelado, 25 créditos para o estágio prático no mestrado, 28 créditos para os trabalhos de final de curso, indicando a preocupação tanto com a formação teórica em conteúdos específicos a serem ensinados, como com a experiência prática e com os fundamentos da educação. Busca-se especializar e preparar o docente para a prática nos anos iniciais, sem deixar de oferecê-lo uma formação ampliada que o permita refletir de forma fundamentada acerca de sua atividade docente na escola.

O que teoricamente se apresenta como um avanço, revela-se, na prática, como uma reforma nociva e contrária aos objetivos pedagógicos. As experiências atuais mostram que nem a mobilidade internacional foi alcançada, nem a evasão dos estudantes diminuiu. As grades curriculares dos cursos das faculdades de educação não ficaram nem mais claras, nem bem definidas, nem comparáveis. Segundo Krautz (2013a), as decisões de Bolonha e os processos desencadeados nas instituições europeias de ensino superior não foram democráticas e, até hoje, não há diálogo nem com os países, nem com as instituições de ensino superior.

Uma justificativa científico-pedagógica para as reformas do Processo de Bolonha permanece inexistente. $\mathrm{O}$ ensino superior foi fragmentado em duas fases e regulamentado por dispositivos, regras, testes, documentações, avaliações e controles que sobrecarregam objetivamente uma abordagem pedagógica mais dinâmica e flexível. O modelo de competência inerente ao processo de Bolonha reflete 
uma percepção tecnicista do que venha a ser a relação ensino-aprendizagem que lhe é subjacente (KRAUTZ, 2013b). Como afirma Frost (Parecer acadêmico para o parlamento do estado sobre a reforma de ensino apresentado no dia 11.02.2016, p. 3), o conceito de competência, que embasa a reforma de Bolonha, baseia-se numa funcionalidade tecnológica e contraria teorias e reflexões básicas pedagógicas. A equação utilitarista de métodos didáticos funcionais em salas de aula para atingir metas, subjacente ao conceito de competência, não contribui nem para a formação docente e muito menos para a formação discente.

A aprendizagem de um agir competente é compreendida de forma utilitarista como saber-usar e saber-aplicar, sem conhecer exatamente, e sem avaliar sistematicamente, os problemas causados por essa prática (princípio do usuário). A educação, ao contrário, deve expor justamente o que é excluído da caixa-preta do conceito de competência: saber agir e discutir objetivamente numa relação interpessoal com conhecimento e responsabilidade (FROST, 2016, p. 2, tradução nossa).

O modelo de Bolonha, por meio da modularização dos cursos de magistério e ênfase tecnicista na competência, substitui a responsabilidade pedagógica do futuro docente por uma tecnologia pedagógica que instrui alunos em vez de lhes despertar o interesse pelo conhecimento.

\section{Reflexões comparativas}

Como podemos perceber, a proposta de formação do docente para os anos iniciais é bastante diferente no Brasil e na Alemanha. Por questões culturais, políticas e sociais, a formação do docente na Alemanha, pelo menos no estado analisado, estrutura-se nos estudos dos fundamentos da educação, bem como na experiência prática e por meio dos conteúdos específicos. São 9.000 horas entre bacharelado e mestrado, somadas às 1.800 horas de estágio de preparação para se tornar um professor dos anos iniciais. No Brasil, são exigidas um mínimo de 3.200 horas de licenciatura, sendo da responsabilidade do curso formar além do professor de anos iniciais, o professor da educação infantil, o gestor e o pesquisador, entre outras modalidades que podem ser trabalhadas conforme interesse da instituição. Ou seja, além de uma carga horária bastante inferior, o curso no Brasil ainda tem o compromisso com formação em outras modalidades. Nesse sentido, não há como negar que a formação do docente é bem mais especializada e aprofundada na Alemanha do que no Brasil. Para Saviani, a formação em pedagogia no Brasil é "extremamente restrita e demasiadamente extensiva: muito restrita no essencial e assaz excessiva no acessório" (2012. p. 58). Ou seja, o curso estaria dilatado, não conseguindo definir o seu objetivo, nem a atividade profissional do pedagogo. 
$\mathrm{Na}$ Alemanha, existem vários cursos de formação de professores, sendo um para a formação exclusiva do docente que irá atuar nos anos iniciais. O estudante deverá estudar 1.650 horas sobre o ensino da língua escrita, 1.650 horas sobre o ensino de matemática, 1.650 horas sobre o ensino de uma outra disciplina que poderá ser escolhida, 360 horas de aprofundamento em uma dessas disciplinas, 1.920 horas de ciências da educação (pelo viés das subdisciplinas - educação, psicologia e sociologia, incluindo estágio de aptidão e orientação e estágio profissional extraescolar), e 750 horas de estágio na escola, 180 horas sobre o ensino da língua alemã para migrantes e $840 \mathrm{~h}$ para a elaboração do trabalho de final do bacharelado e da dissertação no mestrado. Trata-se de uma formação direcionada para a docência na escola de anos iniciais, com uma extensa formação em fundamentos da educação, prática de ensino e conteúdos específicos. Há uma preocupação com a formação de um docente pesquisador, mas não com o gestor.

Já no Brasil, a formação do docente dos anos iniciais, da educação infantil, o gestor e demais modalidades acontece em 3.200 horas, não havendo um percentual estabelecido para área do conhecimento necessário para a docência nesse nível de ensino, o que possibilita uma diversidade de currículos para a mesma formação. Analisando o debate anterior às Diretrizes brasileiras para a formação do pedagogo, realizado no âmbito das principais entidades acadêmicas (Anfope, Anped, Andipe, etc.) e com o Conselho Nacional de Educação, é possível observar a preocupação com uma formação mais geral e em curto prazo de forma que, em pouco tempo, e com diferentes funções, o estudante possa ter acesso ao mundo do trabalho. Além da preocupação com a inserção dos profissionais no mercado de trabalho, existe a compreensão de que não seria adequado reduzir a tarefa do pedagogo apenas a um nível ou a uma modalidade do ensino, tendo em vista a amplitude dessa área do conhecimento. Além disso, uma carga horária maior seria atraente para uma profissão em um país que, ao contrário da Alemanha, é bem desvalorizada.

A compreensão presente nas Diretrizes brasileiras de que a formação do pedagogo estaria identificada com a formação do professor tem potencializado as discussões entre os especialistas. Para Libâneo, no conceito de docência presente nas diretrizes caberia o "planejador da educação, o especialista em avaliação, o animador cultural, o pesquisador, o editor de livros, entre tantos outros" (LIBÂNEO, 2006, p. 845). Segundo o autor (2006), a imprecisão conceitual está nos termos centrais da teoria pedagógica: educação, pedagogia, docência. Ora a docência é colocada como objeto do curso de pedagogia, ora vinculada aos seus objetivos. E ainda, a pedagogia que forma o docente, também formar o planejador, executor e o avaliador das de atividades educativas. Alerta que redação das Diretrizes passa a ideia de que a pedagogia foi substituída pela docência. E ainda, pergunta se cada uma das 
modalidades estabelecidas seria uma área de atuação profissional (habilitaçoes?). Reforça a crítica perguntando: dada a ênfase na formação para a docência nos anos iniciais e na educação infantil, por que a denominação "licenciatura em pedagogia" e não "licenciatura em educação infantil e anos iniciais?" (LIBÂNEO, 2006). Crítica a expectativa de formação brasileira de um superprofissional com várias atribuições docentes, quase todas apresentadas de forma desconectadas, distintas ou sobrepostas entre os artigos do documento.

$\mathrm{Na}$ Alemanha, não há a preocupação com a identidade dos cursos, pois os cursos de formação de docentes não são chamados de pedagogia, mas, sim cursos de formação para o magistério (Lehramt) que se definem pelos diferentes níveis de ensino. Em cada curso, os estudantes estudam teorias pedagógicas e demais ciências da educação específicas para cada nível de ensino nos institutos e faculdades de educação. Para ensinar nos anos iniciais (Grunschulen), deve-se fazer um bacharelado e um mestrado voltado para essa especificidade, inclusive o trabalho de final de curso e a dissertação. As discussões que existem sobre a pedagogia estariam no nível das discussões de identidade da área, não dos cursos de formação de professores. Ou seja, existe um campo científico chamado pedagogia que ultrapassa o nível da docência, que busca refletir, discutir e desenvolver os conhecimentos educacionais que são, obrigatoriamente, estudados durante a formação para o magistério.

Já no Brasil, diante da tentativa de identificar a pedagogia com a formação docente, as diretrizes acabaram desprezando a epistemologia desse campo científico, simplificando os estudos pedagógicos em favor de uma formação genérica. Segundo Franco, Pimenta e Libâneo (2007, p. 91), a Pedagogia no Brasil, expressa uma "concepção simplista, reducionista da pedagogia e do exercício profissional do pedagogo, decorrente de precária fundamentacão teórica, de imprecisões conceituais, de desconsideração dos vários âmbitos de atuação científica e profissional do campo educacional" (FRANCO; PIMENTA; LIBÂNEO, 2007, p. 94), além de não conseguir formar adequadamente o professor.

Cruz (2011), a partir da análise de dezessete entrevistas realizadas com reconhecidos pedagogos brasileiros entre eles, Bernadetti Gatti, Carmem Bissoli da Silva, Ilma Passos Veiga, Maria Amélia Franco, Selma Garrido Pimenta, entre outros, diz que a compreensão existente é de um curso de pedagogia com uma visão "fragmentária de currículo, que tende a gerar um efeito dispersivo do processo formativo, resultando em uma formação de caráter mais abstrato e menos integrado ao campo de atuação do futuro profissional" (CRUZ, 2011, p. 207). Segundo ela, a compreensão de boa parte dos entrevistados foi a de que "a concepção de docência ampliada, concebida articuladamente à gestão e à produção de conhecimento, parece não ser suficiente para favorecer a formação de um profissional que será, ao 
mesmo tempo, professor e pedagogo ou pedagogo porque é professor" (CRUZ, 2011, p. 159).

No que se refere à formação nos conteúdos específicos das disciplinas a serem ensinadas na escola, de forma diferente como acontece no Brasil, na Alemanha é feita nas faculdades específicas, o que permite uma especialização maior nas áreas específicas de ensino. Nos vários institutos/departamentos de educação, estudam-se as ciências da educação, técnicas de didática, trabalho cooperativo, técnicas de avaliação, realizam-se os estágios práticos e elaboram-se os trabalhos de final de curso e de dissertação. Os estudantes dos cursos de magistério ainda são acompanhados pelo Centro de formação de professores (ZfL), não estão concentrados nos institutos ou faculdades de educação como no Brasil. Talvez essa seja uma das dificuldades dos cursos de pedagogia no Brasil, concentrar toda a formação, inclusive das disciplinas específicas, na faculdade de educação, as quais se constituíram, talvez mais pela vinculação fragmentada às áreas e departamentos, interna e externa às faculdades, do que às interações em torno da formação.

Além da possibilidade de aprofundar os estudos das disciplinas a serem ensinadas nos anos iniciais - Língua escrita, Matemática e outra disciplina que pode ser escolhida entre: Música, artes, Religião, esporte, ciência naturais e sociais nas faculdades correspondentes, - o estudante desse nível de ensino tem a oportunidade de realizar um estágio de aptidão na escola (25 dias), de um estágio em outros campos profissionais (4 semanas) no bacharelado e realização de 750 horas de estágio práticos no mestrado, sendo pelo menos 400 horas dentro de sala de aula. E ainda para poder exercer a profissão, deverá, depois de formado, realizar um estágio de preparação de 18 meses. Comparado com o estágio no Brasil, a carga horária de estágio na Alemanha é maior, sendo o tempo de estágio 400 horas apenas na escola de anos iniciais. No Brasil, são 400 horas que devem ser divididas entre o estágio na educação infantil, estágio nos anos iniciais, com a possibilidade de estágios também na gestão e em outros espaços pedagógicos extraescolares. As Diretrizes apontam a preocupação com a experiência prática, mas pela demanda dos objetivos da formação, os estágios acabam acontecendo, segundo Gatti, de forma superficial, muitas vezes, se caracterizando como práticas efetivas dos estudantes de pedagogia nas escolas (2010, p. 1371). Isso significa que embora as diretrizes de 2015 tenham ampliado o tempo de estágio no Brasil, a prática para o magistério nos anos iniciais, exigida pelo processo de Bolonha e realizada pela LABG de 2009, é mais ampliada na Alemanha. Assim como no Brasil, se destaca, nas Diretrizes para a formação para o magistério na Alemanha, uma notável preocupação com a qualidade da profissionalização do professor, por isso, a ênfase nos estágios. No entanto, o dilema da formação 
no Brasil é de que um único currículo busca formar o profissional em diferentes modalidades, o que pode oportunizar uma formação profissional mais enfraquecida conforme apontam os especialistas (GATTI, 2010; SAVIANI, 2010; LIBÂNEO, 2006; PIMENTA, 2007).

Percebe-se, atualmente, tanto no Brasil como na Alemanha uma forte indução das políticas educacionais para que os cursos de formação docente sejam pensados a partir do que é demandado pela escola básica. Há uma preocupação em qualificar a escola básica a partir da formação de seus docentes. Na Alemanha, a aproximação e o diálogo entre universidade e a escola é facilitado pelo Centro de formação de professores existente nas universidades. No Brasil, as novas diretrizes (2015) apontam a necessidade de uma articulação entre o Projeto Desenvolvimento Institucional (PDI), o Projeto Pedagógico Institucional (PPI) e o Projeto Pedagógico de Curso (PPC) com a escola básica. Ou seja, ambos os países caminham para uma aproximação, cada vez maior, da universidade com a escola.

Entretanto, mesmo diante de inúmeras diferenças, é possível perceber tanto no Brasil como na Alemanha, um enfoque na profissionalização do docente, por isso, a ênfase na formação das competências, tendência essa decorrente dos desdobramentos econômicos, políticos, culturais e educacionais do processo de globalização internacional. No entanto, no Brasil, tal profissionalização ainda é muito precária, tendo em vista a compreensão de que é possível formar um profissional em diferentes modalidades num único curso. Perguntamos: qual seria o caminho mais viável para a formação de professores para nos anos iniciais no Brasil? O que podemos aprender com o contexto alemão? Sem dúvida, na Alemanha, o profissional é melhor preparado para a docência nos anos iniciais, devendo entretanto, cursar, obrigatoriamente, o bacharelado e o mestrado (9.000 horas), o que não seria estimulante para o estudante brasileiro, tendo em vista a desvalorização do profissional da educação no país. Enfim, podemos dizer que há, nos dois países, uma tendência de tornar a formação docente mais próxima da escola, mas que devido as diferenças contextuais, apresentam condutas diferentes, porém não sem problemas. Na Alemanha, há várias críticas em relação tal modelo baseado na formação de competências, tendo em vista a tecnificação da formação educacional. No Brasil, não se conseguiu ainda nem uma boa formação técnica, tendo em vista as diversas e confusas orientações das diretrizes nacionais. 


\section{Considerações finais}

Conforme análises de Dias Sobrinho, "no plano ideológico, a globalização da economia vem naturalizando a conexão entre os mercados e os sistemas de educação" (2014, p. 350), revestindo-se de organizações multilaterais para disseminar ideologias e práticas de hegemonia local, contribuindo para legitimar políticas educacionais setoriais, modelos de desempenho e de avaliação, etc., conectando as finalidades das universidades, da Educação Superior e da Educação Básica com a economia globalizada. Nesse contexto, a diversidade dos atores sociais e de seus interesses e valores, os objetivos da cidadania nacional, entre outros aspectos, coexistem em relações concorrentes, complementares e antagônicas com as demandas da sociedade de economia global. As reformas, as rápidas mudanças e as incertezas produzem modelos educacionais e formativos que se distinguem e se hibridizam.

Nesse sentido, as diretrizes para a formação de professores dos anos iniciais, vinculado a um grande espectro de reformas nas políticas educacionais, incidem sobre as concepções de identidade docente, sobre a reconfiguração do conjunto de valores e de processos formativos da Educação Básica e sobre as noções de formação e de organização dos currículos na Educação Superior. O tempo de formação destinado aos estágios e à interação com as escolas expressa a centralidade do desenvolvimento de habilidades e competências para o ensino e socialização profissional, reorganizam as tensões entre conhecimentos científicos específicos e os conhecimentos pedagógicos, os conteúdos que integram esses conjuntos, seus lugares e fontes autorizadas, bem como as interações entre as instituições formativas. $\mathrm{O}$ foco profissionalização da formação universitária decorre do princípio de racionalidade adotado no contexto internacional fruto dos processos de transferência ou imposição de modelos educacionais padronizados.

Por força de dinâmicas transnacionais, justificadas com o aprofundamento da unidade europeia e com a competitividade deste espaço econômico e político, ocorreu na Alemanha uma reforma do ensino superior que redesenhou o modelo de formação de professores. No contexto brasileiro, o modelo de curso de pedagogia procurou atender, principalmente, às demandas de qualificação da escola básica, tendo em vista a pressão em torno do baixo desempenho dos estudantes nas avaliações internacionais. O que fica evidente é que, embora no Brasil a profissionalização seja mais enfraquecida do que na Alemanha, percebe-se nos dois países o foco no desenvolvimento da escola básica no sentido e uma tendência à tecnificação do ensino, o que pode significar uma preocupação em melhorar o conceito educacional dos países diante dos organismos internacionais e atender, principalmente, ao mercado de trabalho. Ou seja, os contextos embora diferentes e com perspectivas e 


\section{dificuldades formativas diferentes, de alguma forma seguem uma mesma tendên- cia internacional de uma formação universitária, cada vez mais tecnificada, menos emancipadora.}

\section{Notas}

1 O Plano Nacional de Educação (PNE) 2014-2020 indica como estratégia da meta 12: que as instituições deverão assegurar, no mínimo, dez por cento do total de créditos curriculares exigidos para a graduação em programas e projetos de extensão universitária, orientando sua ação, prioritariamente, para áreas de grande pertinência social" (BRASIL, 2014).

2 A formação escolar na Alemanha é pública e gratuita do 1ano à Universidade. Existem poucas escolas privadas, como é o caso de escolas confessionais e escolas que seguem uma filosofia própria, por exemplo: escolas Waldorf, Reggio, entre outras.

3 Na Alemanha, a denominação professor é apenas para quem tem habilitação para a cátedra e ensina na universidade. Professoras e professores de escolas recebem o título de Lehrerin ou Lehrer.

4 Nível elementar (do $1^{\mathrm{o}}$ ao $4^{\mathrm{o}}$ ano, obrigatório), nível secundário I (do $5^{\mathrm{o}}$ ao $8^{\mathrm{o}}-10^{\circ}$ ano obrigatório) e nível secundário II (do $11^{\circ}$ ao $12-13^{\circ}$ ano).

5 No final da Escola Elementar (do 1 ao 4 anos), os pais decidem (com sugestões dos professores) o tipo de nível secundário I que desejam para os seus filhos. A Hauptschule ( $5^{\circ}$ ao $9^{\circ}$ ano) é denominada escola principal, é a escola com a menor exigência de desempenho escolar que prepara os estudantes para as escolas profissionalizantes (pedreiro, cabelereiro, motoristas, etc). A Realschule (5 ao $10^{\circ}$ ano) é orientada para um conhecimento técnico e prático, habilita o alunos para cursos profisisonalizantes mais adiantados (técnico em radiologia, técnico de informática, etc). O Gymnasium ( $5^{\circ}$ ao $12^{\circ} / 13^{\circ}$ ano) é a escola com a maior exigência de desempenho escolar, cujos alunos podem fazer cursos técnicos superiores e /ou ingressar numa instituição de ensino superior. A Gesamtschule é uma escola alternativa ao tripé hierárquico do sistema escolar alemão (Gymnasium, Realschule, Hauptschule), onde as três formas coexistem numa mesma escola. A vantagem da Gesamtschule é que a decisão sobre qual tipo de escola o aluno irá frequentar não precisa ser tomada no $4^{\circ}$ ano do ensino fundamental.

6 O centro de formação de docentes (Zentrum für Lehrerbildung, ZfL) é uma unidade independente na universidade responsável pelo incentivo interdisciplinar/transdisciplinar da formação acadêmica dos docentes e aconselha a reitoria sobre todas as questões neste domínio. Os objetivos dos centros (ZfL) residem nas áreas de aconselhamento do aluno e coordenação do curso, fases práticas, assim como pesquisa, aplicação dos saberes (Transfer) e aperfeiçoamento. A ideia é que esses centros fortaleçam as disciplinas que serão ensinadas nas escolas, suas didáticas e avaliações específicas e assim como as ciências da formação na universidade. Além disso, os $Z f L$ incentivam a intensificação da mediação (redes, canais de comunicação com as escolas) na formação dos docentes. Os centros de formação para o magistério (Zentren für Lehrerbildung - ZfL) no estado da Renânia do Norte-Vestfália existem desde a década de 1990, com exceção de Bielefeld, cujo centro foi fundado em 1980. As universidades de Dortmund, Münster, Paderborn e Wuppertal participam, desde 1995, do modelo experimental do estado criando os centros para a docência em suas instituições. As universidades de Siegen e Bochum formaram os seus centros em 1997 e 1998 respectivamente" (BLÖMEKE, 2000, p. 255).

7 Segundo as leis de diretrizes do Estado (LABG, 2009), 1 crédito (ECTS) corresponde a 1 hora/aula e a 30 horas de estudo individual do estudante fora da sala de aula. Assim sendo, em teoria, 300 créditos (180 do bacharelado e 120 do mestrado) correspondem a 9000 horas de estudo do aluno.

\section{Referências}

BRASIL. Conselho Nacional de Educação. Parecer CNE/CP nº 5, de 13 de dezembro de 2005. Brasília, DF, 2005.

. Conselho Nacional de Educação. Parecer CNE/CP no 2, de 25/06/2015. Brasília, 2015. . Conselho Nacional de Educação. Resolução nº 2. 01/07/2015. 
. Lei no 9.394, de 20 de dezembro de 1996. Brasília, DF, 1996.

Plano Nacional de Educação 2014-2024: Lei no 13.005, de 25 de junho de 2014, que aprova o Plano Nacional de Educação (PNE) e dá outras providências. Brasília: Câmara dos Deputados, Edições Câmara, 2014.

16 maio 2006.

Resolução no 1, de 15 de maio de 2006. Diário Oficial da União, n. 92, seção 1, p. 11-12,

CRAMER, Colin. Theorie und Praxis in der Lehrerbildung. Bestimmung des Verhältnisses durch Synthese von theoretischen Zugängen, empirischen Befunden und Realisierungsformen. Die Deutsche Schule 106, H. 4, p. 344-357, 2014.

CRUZ, Gisele Barreto da. Curso de pedagogia no Brasil: história e formação com pedagogos primordiais. Rio de Janeiro: Wak, 2011.

COMBE, Arno; KOLBE, Fritz-Ulrich. Lehrerprofissionalität: Wissen, Können, Handeln. In: Werner Helsper. Handbuch der Schulforschung. Wiesbaden: VS Verlag für Sozialwissenschaften, 2008. p. 857-875.

COWEN, Robert; KAZAMIAS, Andreas M.; ULTERHALTER, Elaine (Org.). Educação compara$d a$ : panorama internacional e perspectivas. Brasília: Capes; Unesco, 2012. v. 2.

DALE, Roger; ROBERTSON, Susan. Além dos "ismos" metodológicos na educação comparada emu ma era de globalização. In: COWEN, Robert; KAZAMIAS, Andreas M.; ULTERHALTER, Elaine. (Org.). Educação comparada: panorama internacional e perspectivas. Brasília: Capes; Unesco, 2012. v. 2.

. Globalização e educação: demonstrando a existência de uma "cultura educacional mundial comum" ou localizando uma "agenda globalmente estruturada para a educação"?. Educação \& Sociedade, Campinas, v. 25, n. 87, p. 423-460, maio/ago. 2004.

DIAS SOBRINHO, José. Educação superior na sociedade da economia do conhecimento e da informação: novas demandas, novos papéis. In: MÜHL, Heldon H.; GOMES, Luiz R.; ZUIN, Antonio A. S. (Org.). Teoria crítica, filosofía e educação: homenagem a Pedro L. Goergen. Passo Fundo: UPF Editora; Maringá: Editora da Universidade Estadual de Maringá, 2014.

DOURADO, Luiz. Diretrizes curriculares nacionais para a formação inicial e continuada dos profissionais do magistério da educação básica: concepções e desafios. Educação \& Sociedade, Campinas, v. 36, n. 131, p. 299-324, abr./jun. 2015.

FRANCO, Maria Amélia Santoro; LIBÂNEO, José Carlos; PIMENTA, Selma Garrido. Elementos para a formulação de diretrizes curriculares para cursos de pedagogia. Cadernos de Pesquisa, v. 37 , n. 130 , jan. 2007 .

FROST, Ursula. Stellungnahme zum Gesetzentwurf der Landesregierung für ein "Gesetz zur Änderung des Lehrerausbildungsgesetzes" (Parecer acadêmico para o parlamento estadual). Drucksache 16/9887. Köln, 11 fev. 2016.

GATTI, Bernadetti. Formação de professores no Brasil: características e problemas. Educação \& Sociedade, Campinas, v. 31, n. 113, p. 1355-1379, out./dez. 2010.

GOERGEN, Pedro L. Educação comparada: uma disciplina atual ou obsoleta? Revista Pro-Posições, Revista da Faculdade de Educação, Campinas, v. 2, n. 3, p. 6-19, dez. 1991. 
HÖRSTER, Reinhard. Bildung. In: KRÜGER, Heinz-Herrmann; HELSPER, Werner. Einführung in die Grundbegriffe und Grundfragen der Erziehungswissenschaft. Opladen \& Farmington Hills, 2010. p. 46.

KOTTHOFF, Hans-Georg; KLERIDES, Eleftherios (Ed.). Governing Educational Spaces. Knowledge, Teaching, and Learning in Transition. Rotterdam: Sense Publ., 2015.

KUHN, Hans-Jürgen. Anspruch, Wirklichkeit und Perspektiven der Gesamtstrategien der KMK zur Bildungsmonitoring. Die Deutsche Schule 106, H. 4, p. 414-426, 2014.

KMK - Conferência dos Ministros da Cultura (2010): Ländergemeinsame inhaltliche Anforderungen für die Fachwissenschaften und Fachdidaktiken in der Lehrerbildung (Beschluss der Kultusministerkonferenz vom 16.09.2010).

KMK - Conferência dos Ministros da Cultura (2011): Lehrereinstellungsbedarf und Lehrereinstellungsangebot in der Bundesrepublik Deutschland. Modellrechnung 2010-2020 (Junho de 2011).

KRAUTZ, Jochen. Bildungsreform und Propaganda. In: U. Frost \& Rieger-Ladich. Demokratie setzt aus. Gegen die sanfte Liquidation einer politischen Lebensform. Sonderheft der Vierteljahresschrift für wissenschaftliche Pädagogik. Paderborn, 2013a. p. 86-128.

Auf dem Niveau eines Heizungsthermostaten. In: Frankfurter Allgemeine Zeitung vom 30.08.2013, p. 7, 2013b.

LABG. Lei de Formação de Professores (Lehrerausbildungsgesetz - LABG), 2009. Ministerium für Schule und Weiterbildung des Landes Nordrhein-Westfalen. Disponível em: <www.schulministerium.nrw.de/BP/Schulrecht/Lehrerausbildung/LABGNeu.pdf>. Acesso em: 22 out. 2016.

LIBÂNEO, José Carlos. Diretrizes curriculares da pedagogia: imprecisões teóricas e concepção estreita da formação profissional de educadores. Educação \& Sociedade, Campinas, v. 27, n. 96 - Especial, p. 843-876, out. 2006.

LZV - Decreto de acesso ao magistério (Lehramtzugangsverordnung - LZV), 2009. Ministerium für Schule und Weiterbildung des Landes Nordrhein-Westfalen. Disponível em: <www.schulministerium.nrw.de/BP/Schulrecht/Lehrerausbildung/LABGNeu.pdf>. Acesso em: 22 out. 2016.

MALET, Régis. Do estado-nação ao espaço-mundo: as condições históricas da renovação da educação comparada. Educação \& Sociedade, v. 25, n. 89, p. 1301-1332, 2004.

MONARCHA, Carlos; LOURENÇO FILHO, Ruy. Educação comparada. Brasília: MEC/Inep, 2004.

OELKERS, Jürgen. Probleme der Lehrerbildung nach Bologna. Palestra realizada na Universidade de Erfurt no dia 08.06.2012. Disponível em: <www.ife.uzh.ch/research/emeriti/oelkersjuergen/vortraegeprofoelkers/vortraege2012/Erfurt_LAB.pdf>. Acesso em: 22 out. 2016.

PUDERBACH, Rolf. Wer Studiert Sekundarstufe-I-Lehramt? Die Bedeutung von sozialer Herkunft und Bildungsbiografie für die Schulformwahl von Lehramsstudierenden am Beispiel der sächsischen Mittelschule. Die Deutsche Schule 108, H. 1, p. 47-66, 2016. 
RICARTE LANZ, Helza. O semestre prático na formação de professores do ensino fundamental e médio da Universidade de Colônia, Alemanha. In: CEBRIAN-DE-LA-SERNA, M.; SERRANO-ANGULO, J.; RUIZ REYS, F. J. (Ed.). Tecnologias para a avaliação do estágio e práticas externas em contextos multidisciplinares. [S.l.]: Universidade de Málaga, 2016. (Coleção Gtea).

ROTERS, Bianca. Professionalisierung durch Reflexion in der Lehrerbildung. Eine empirische Studie an einer deutschen und einer US-amerikanischen Universität. Münster: Waxmann, 2012.

SAVIANI, Dermeval. A Pedagogia no Brasil: história e teoria. 2. ed. Campinas: Autores Associados, 2012.

TERHART, Ewald. Dauerbaustelle Lehrerbildung. Eine Bestandsaufnahme aus Sicht der Bildungswissenschaften. In: HOCHSCHULREKTORENKONFERENZ (Org.). Lehrerbildung heute. Impulse für Studium und Lehre. Projekt Nexus - Konzepte und gute Praxis für Studium und Lehre. Bonn: HRK, 2014. Disponível em: <https://www.hrk.de/uploads/media/270626_HRK_ Lehrerbildung_web_02.pdf>. Acesso em: 22 out. 2016.

WALM, Maik; WITTEK, Doris. Lehrer_innenbildung in Deutschland im Jahr 2014. Eine phasenübergreifende Dokumentation der Regelungen in den Bundesländern. Eine Expertise im Auftrag der Max-Traeger-Stiftung. Frankfurt am Main: GEW. Disponível em: <http://gew.de/ Binaries/Binary98423/Lehrer-Innenbildung_2014_A4_web.pdf>. Acesso em: 22 out. 2016. 